\title{
Phosphate ion adsorption properties of PAN-based activated carbon fibers prepared with $\mathrm{K}_{2} \mathrm{CO}_{3}$ activation
}

\author{
Tomoyoshi Sakamoto ${ }^{1}$ (D) $\cdot$ Yoshimasa Amano ${ }^{2,3} \cdot$ Motoi Machida $^{2,3}$
}

Received: 30 October 2019 / Accepted: 10 March 2020 / Published online: 19 March 2020

(c) Springer Nature Switzerland AG 2020

\begin{abstract}
Adsorbents for phosphate ion removal were prepared with $\mathrm{K}_{2} \mathrm{CO}_{3}$ activation and heat treatment at $950{ }^{\circ} \mathrm{C}$ from polyacrylonitrile-based carbon fiber (PAN-CF). Comparative tests for specific surface area and pore structures, elemental and nitrogen species analysis, and phosphate ion adsorption experiments demonstrated that $K(3)-\Delta$, which was activated with $\mathrm{K}_{2} \mathrm{CO}_{3} / \mathrm{PAN}-\mathrm{CF}$ weight ratio of 3 and then treated at $950^{\circ} \mathrm{C}$, exhibited larger amount of quaternized-nitrogen $(0.46 \mathrm{wt} \%)$ and equilibrium adsorption amount $(0.23 \mathrm{mmol} / \mathrm{g})$ among the prepared adsorbents. The experimental data for phosphate adsorption of $\mathrm{K}(3)-\Delta$ was well fitted to Langmuir adsorption isotherms and pseudo-second-order kinetic model. As for regeneration performance, $\mathrm{K}(3)-\Delta$ still remained more than $60 \%$ adsorption amount of the fresh adsorbent after rejuvenation treatment.
\end{abstract}

Keywords Polyacrylonitrile-based activated carbon fiber $\cdot$ Phosphate ion adsorption $\cdot \mathrm{K}_{2} \mathrm{CO}_{3}$ activation $\cdot$ Quaternizednitrogen · Adsorption mechanism · Regeneration

\section{Introduction}

Phosphorus $(P)$ is one of the essential nutrients for animals and plants [1]. On the other hand, it causes water quality deterioration such as algal blooms and red tide through discharging phosphate and other nutrients into closed water area by daily human activities $[2,3]$. The wastewater exhausted from houses, factories, fields, and farms contains a great amount of phosphorus exceeding the regulation. Chiba prefectural assembly, Japan, has made efforts so that farmers and livestock farmers should restrict dischargeable $P$ concentration of less than $8 \mathrm{mg} / \mathrm{L}$ and encouraged the citizen to reduce nutrients in domestic wastewater in the Environmental White Paper of FY 2017. Lake Inba and Lake Tega were the first and second largest lake in Chiba prefecture, Japan [4], and their environmental standards of total phosphorus (TP) were regulated less than 0.03 and $0.1 \mathrm{mg} / \mathrm{L}$, respectively [5]. However, according to the Environmental White Paper of FY2017, the TP concentrations in both lakes obviously exceeded the standard values $(0.14$ and $0.15 \mathrm{mg} / \mathrm{L}$, respectively), and they were reported to be the first and third worst eutrophic lake in Japan in 2016 by the Ministry of the Environment, Government of Japan [4]. The World Health Organization (WHO) also recommends phosphate ion concentration of less than $5 \mathrm{mg} / \mathrm{L}$ in natural water [6], though water blooms have broken out in China and Southeast Asia frequently $[1,7,8]$. In order not to occur water environmental problems, it is important to not only reduce releasing nutrients into natural water but also remove phosphate from wastewater [9-11].

Generally, phosphate has been removed with coagulating sedimentation method at sewage treatment facility $[6$, 12 ]. The problems of this method were to produce a large

$\triangle$ Tomoyoshi Sakamoto, adya2406@chiba-u.jp| ${ }^{1}$ Graduate School of Science and Engineering, Chiba University, 1-33, Yayoi-cho, Inage-ku, Chiba 263-8522, Japan. ${ }^{2}$ Graduate School of Engineering, Chiba University, 1-33, Yayoi-cho, Inage-ku, Chiba 263-8522, Japan. ${ }^{3}$ Safety and Health Organization, Chiba University, 1-33, Yayoi-cho, Inage-ku, Chiba 263-8522, Japan. 
amount of waste and not to able to reuse the phosphorus resources. Although calcium superphosphate is produced from rock phosphorus with sulfuric acid as a low-cost phosphorus nutrient for crops, the rock phosphorus output has been decreasing year by year [13]. To solve these problems, adsorption method has been studied in order to remove $\mathrm{P}$ from environmental water and recycle as a nutrient [14-18].

Various adsorbents were widely investigated for phosphate removal, such as $\mathrm{Ca}$ and $\mathrm{Mg}$ modified adsorbent [19], Fe-Mn oxide [20], Fe-Al oxide [21], zeolite [22], Albiochar [23], activated carbon [24], iron oxide coated activated carbon [25], and Ln-doped activated carbon [26]. Most of adsorbents were prepared with metal ions as adsorption site [27-29]. This preparation method could innovate high-performance adsorption ability for any material as well as metal ions such as Mg and Ca could be introduced onto its surface. However, there were also disadvantages such as their low adsorption capacities and the environmental damage due to releasing the surplus metals. Ion exchange resin is high cost to be purchased [30] and not robustness against heating conditions. In this study, adsorbents were prepared from frame-resistant polyacrylonitrile-based carbon fiber (PAN-CF), PYROMEX (PYR), with $\mathrm{K}_{2} \mathrm{CO}_{3}$ activation. In previous studies, the nitrogen contained in PAN-CF would be quaternized through heat treatment at over $500{ }^{\circ} \mathrm{C}[31,32]$, and PAN-ACF treated at $950^{\circ} \mathrm{C}$ had the maximum adsorption amount [33]. The positively charged quaternized-nitrogen (N-Q) could be effective adsorption site for phosphate anion. On the other hand, the negatively charged pyridine/pyrrole $\mathrm{N}$-oxide $(\mathrm{N}-\mathrm{X})$ and oxygen functional groups might prevent phosphate ion from approaching onto the adsorbent surface. In order to obtain higher phosphate adsorption amount, both the more amount of nitrogen and the higher proportion of $\mathrm{N}-\mathrm{Q}$ in the adsorbent are essential. Therefore, PYR should be activated mildly to remain the nitrogen adsorption site on the adsorbent.

In this study, $\mathrm{K}_{2} \mathrm{CO}_{3}$ was used as a chemical activator for developing the specific surface area and pore structures of PYR. Generally, the activators for chemical activation such as $\mathrm{KOH}$ [34], $\mathrm{ZnCl}_{2}$ [35], and $\mathrm{H}_{3} \mathrm{PO}_{4}$ [36] have been studied widely to prepare high performance activated carbons from various raw materials. On the other hand, there are a few studies on $\mathrm{K}_{2} \mathrm{CO}_{3}$ activation method because $\mathrm{K}_{2} \mathrm{CO}_{3}$ shows less activation ability compared to $\mathrm{KOH}$ [37]. In our previous study, the $\mathrm{KOH}$-activated PYR adsorbed phosphate ion of $0.1 \mathrm{mmol} / \mathrm{g}$, though steam-activated PYR adsorbed $0.2 \mathrm{mmol} / \mathrm{g}$ [38]. The low adsorption amount of $\mathrm{KOH}$-activated PYR would be caused by its low nitrogen content. $\mathrm{KOH}$ reacts with both carbon and nitrogen strictly causing the decrease in yield, specific surface area and pore structures. It is well known that $\mathrm{KOH}$ activation is processed through some chemical reaction as follows $[39,40]$;

$6 \mathrm{KOH}+\mathrm{C} \rightarrow 2 \mathrm{~K}+3 \mathrm{H}_{2}+2 \mathrm{~K}_{2} \mathrm{CO}_{3}$

$\mathrm{K}_{2} \mathrm{CO}_{3} \rightarrow \mathrm{K}_{2} \mathrm{O}+2 \mathrm{CO}_{2}$

$2 \mathrm{~K}+\mathrm{CO}_{2} \rightarrow \mathrm{K}_{2} \mathrm{O}$

$\mathrm{K}_{2} \mathrm{O}+\mathrm{C} \rightarrow 2 \mathrm{~K}+\mathrm{CO}$

$\mathrm{K}_{2} \mathrm{CO}_{3}+\mathrm{C} \rightarrow \mathrm{K}_{2} \mathrm{O}+2 \mathrm{CO}$

The Eq. (5) shows that $\mathrm{K}_{2} \mathrm{CO}_{3}$ also reacts with carbon and activates the material like $\mathrm{KOH}$. When the activation process starts with $\mathrm{K}_{2} \mathrm{CO}_{3}$, the raw material is activated through only Eqs. (2)-(5). It means that carbon and nitrogen react mildly with $\mathrm{K}_{2} \mathrm{CO}_{3}$ compared to $\mathrm{KOH}$, leading to the restriction of nitrogen decrease. Moreover, $\mathrm{K}_{2} \mathrm{CO}_{3}$ is weaker basic chemical, so it damages the environment less than $\mathrm{KOH}$.

\section{Materials and methods}

\subsection{Materials}

The adsorbent used in the experiments was prepared from polyacrylonitrile carbon fiber, PYROMEX (PYR), which was purchased from Toho Tenax Co., Ltd., Japan. The PYR contains $20.9 \mathrm{wt} \%$ nitrogen and has $7 \mathrm{~m}^{2} / \mathrm{g}$ specific surface area. All reagents such as potassium dihydrophosphate, hydrochloric acid, and potassium carbonate were purchased from Kanto Chemical Co., Ltd., Japan. Phosphate ion $\left(\mathrm{PO}_{4}{ }^{3-}\right)$ stock solution ( $3 \mathrm{mmol} / \mathrm{L}$ ) was prepared by dissolving $\mathrm{KH}_{2} \mathrm{PO}_{4}$ in deionized water.

\subsection{Preparation for adsorbents}

The PYR was dried in an oven at $110^{\circ} \mathrm{C}$ for $1 \mathrm{~h}$ to remove the moisture. Approximately $3 \mathrm{~g}$ of dried-PYR was mixed with $\mathrm{K}_{2} \mathrm{CO}_{3}$ solid in a ceramic boat and heated up to $800^{\circ} \mathrm{C}$ $\left(10{ }^{\circ} \mathrm{C} / \mathrm{min}\right)$ and then maintained at $800^{\circ} \mathrm{C}$ for $30 \mathrm{~min}$ under $\mathrm{N}_{2}$ gas flow using a horizontal tubular furnace. The weight ratio of $\mathrm{K}_{2} \mathrm{CO}_{3}$ /PYROMEX were $1,2,3,4$, and 5. The activated-PYR was washed using $1 \mathrm{~mol} / \mathrm{L} \mathrm{HCl}$ and hot distilled water. After drying in an oven at $110^{\circ} \mathrm{C}$ for $24 \mathrm{~h}$, the sample was heated up to $950^{\circ} \mathrm{C}\left(10^{\circ} \mathrm{C} / \mathrm{min}\right)$ and then kept for $30 \mathrm{~min}$ to transform the nitrogen species into $\mathrm{N}-\mathrm{Q}$. The adsorbents were designated as $\mathrm{K}(\mathrm{x})-\Delta$, where $\mathrm{x}$ is the weight ratio of activator $\left(\mathrm{K}_{2} \mathrm{CO}_{3} / \mathrm{PYR}\right)$. In order to compare with $\mathrm{K}(\mathrm{x})-\Delta$, PYR activated by $\mathrm{K}_{2} \mathrm{CO}_{3}$ (without heat 
treatment at $950^{\circ} \mathrm{C}$ ) was also prepared and named as $\mathrm{K}(\mathrm{x})$ as a reference adsorbent.

\subsection{Adsorption experiments}

The adsorbents prepared at different activator ratios were compared each other for phosphate adsorption amount through batch experiments. After drying in oven at $110^{\circ} \mathrm{C}$ for $1 \mathrm{~h}$, approximately $30 \mathrm{mg}$ of adsorbent and $15 \mathrm{~mL}$ of $3 \mathrm{mmol} / \mathrm{L} \mathrm{KH}_{2} \mathrm{PO}_{4}$ solution were mixed in $30 \mathrm{~mL}$ conical flask and capped. The initial solution $\mathrm{pH}$ was around 4.7, and the solution $\mathrm{pH}$ was not adjusted before adsorption experiments, except for examining the effect of $\mathrm{pH}$ on phosphate adsorption. These flasks were placed in a thermostat shaker and agitated at $25^{\circ} \mathrm{C}$ and $100 \mathrm{rpm}$ for $24 \mathrm{~h}$. In this study, the concentration of the phosphate ion $\left(\mathrm{PO}_{4}{ }^{3-}\right)$ in the solution was determined by a UV-Vis spectrophotometer (Shimadzu UV-2550, Japan) using the molybdenum blue colorimetric method. The equilibrium adsorption amount $\left(Q_{e^{\prime}} \mathrm{mmol} / \mathrm{g}\right)$ was calculated from Eq. (6) [41];

$Q_{e}=\frac{\left(C_{0}-C_{e}\right) v}{m}$,

where $C_{0}$ and $C_{e}$ are the initial and equilibrium concentration $(\mathrm{mmol} / \mathrm{L})$, respectively, and $v$ is the volume of the solution (L), and $m$ is the weight of adsorbent $(\mathrm{g})$.

\subsection{Adsorption isotherm}

Approximately $30 \mathrm{mg}$ of adsorbent (K(3) or $\mathrm{K}(3)-\Delta)$ and $15 \mathrm{~mL}$ of phosphate ion solution were added into a conical flask with different initial concentrations ranged from 0.1 to $10 \mathrm{mmol} / \mathrm{L}$. These flasks were shaken at $25^{\circ} \mathrm{C}$ with the speed of $100 \mathrm{rpm}$ using thermostat shaker for $24 \mathrm{~h}$. The concentration of phosphate ion in the agitated solution was determined by the same method mentioned in the Sect. 2.3. Adsorption isothermal properties were fitted by the Langmuir model. The maximum adsorption capacity $\left(Q_{\mathrm{m}^{\prime}} \mathrm{mmol} / \mathrm{g}\right)$ and equilibrium adsorption affinity $\left(K_{\mathrm{e}}, \mathrm{L} /\right.$ mmol) were calculated from Eq. (7) [23];

$$
\frac{C_{\mathrm{e}}}{Q_{\mathrm{e}}}=\frac{C_{\mathrm{e}}}{Q_{\mathrm{m}}}+\frac{1}{Q_{\mathrm{m}} K_{\mathrm{e}}}
$$

\subsection{Adsorption kinetics}

The equilibrium adsorption times were determined through the adsorption kinetics experiments. Approximately $150 \mathrm{mg}$ of adsorbents (K(3) or K(3)- $\Delta$ ) were impregnated into $75 \mathrm{~mL}$ of $3 \mathrm{mmol} / \mathrm{L}$ phosphate ion solution in a $200 \mathrm{~mL}$ conical flask. These flasks were capped and shaken at $25^{\circ} \mathrm{C}$ with the speed of $100 \mathrm{rpm}$ using thermostat shaker for $24 \mathrm{~h}$. The concentration of phosphate ion in the agitated solution was determined by the same method mentioned in the Sect. 2.3.

\subsection{Characterization}

Nitrogen adsorption/desorption (BELSORP-mini Il, Microtrac BEL Co., Ltd.) at $-196{ }^{\circ} \mathrm{C}$ was used to calculate the specific surface area and pore volume of mesopore (the pore diameter ranges in 2-50 nm) and micropore (less than $2 \mathrm{~nm}$ ). Before analysis, the sample was outgassed at $300^{\circ} \mathrm{C}$ for $1 \mathrm{~h}$. The specific surface area $\left(S_{B E T}\right)$ was obtained by BET method. The total pore volume $\left(V_{\text {total }}\right)$ and pore average diameter $\left(D_{\text {avg }}\right)$ were calculated using nitrogen adsorption amount and $S_{\mathrm{BET}}$, and micro pore volume $\left(V_{\text {micro }}\right)$ was calculated by subtracting method using $a_{s}$ plots [42]. The elemental contents of $\mathrm{C}, \mathrm{H}$, and $\mathrm{N}$ were determined using Perkin Elmer 2400 II (Perkin Elmer Japan Co., Ltd.). O content was calculated to subtract $\mathrm{CHN}$ amounts from $100 \mathrm{wt} \%$ because $\mathrm{X}$-ray photoelectron spectroscopy analysis had detected only $C, N$, and $\mathrm{O}$ as elemental contains in PYR. The XPS measurement was conducted with the binding energy $392-408 \mathrm{eV}$ to analyze the $\mathrm{N}$ functional species such as $\mathrm{N}-6(398.6 \pm 0.3 \mathrm{eV}), \mathrm{N}-5$ $(400.5 \pm 0.3 \mathrm{eV}), \mathrm{N}-\mathrm{Q}(401.3 \pm 0.3 \mathrm{eV})$, and N-X $(402-405 \mathrm{eV})$ [31].

\subsection{Desorption experiments}

One of the advantages using activated carbon for adsorption is the ability of regeneration and reuse. Regeneration of adsorbent was done with three desorption solutions such as $\mathrm{HCl}(0.5,1$, and $2 \mathrm{~mol} / \mathrm{L}), \mathrm{NaCl}(1 \mathrm{~mol} / \mathrm{L})$ or $\mathrm{NaOH}(1 \mathrm{~mol} / \mathrm{L})$. Moreover, in order to desorb phosphate ion from adsorbent completely, the adsorbent was heated up to $950^{\circ} \mathrm{C}\left(10^{\circ} \mathrm{C} /\right.$ $\mathrm{min}$ ) and then kept for $30 \mathrm{~min}$. The adsorbent after adsorption experiments (following the method of Sect. 2.3) was filtered with filter paper and washed by distilled water. For desorption, the adsorbent was agitated in the chemical solution for $24 \mathrm{~h}$ at $25^{\circ} \mathrm{C}$ and $100 \mathrm{rpm}$. After that, the desorption solution was decanted, and the adsorbent was washed with hot distilled water using Soxhlet extractor until solution $\mathrm{pH} 5$ was established. As for heating method, the washed adsorbent was dried in an oven at $110^{\circ} \mathrm{C}$ overnight, and then inserted into tubular furnace. During the heat treatment, $\mathrm{N}_{2}$ gas continuously flowed at $100 \mathrm{~mL} / \mathrm{min}$, and the temperature was fixed at $950^{\circ} \mathrm{C}$ for $30 \mathrm{~min}$. 


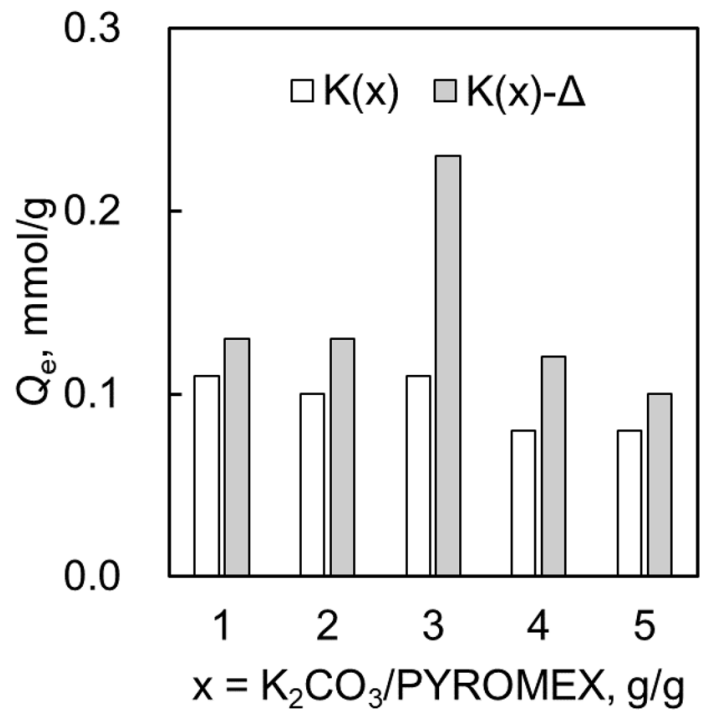

Fig. 1 The equilibrium phosphate adsorption amount of $\mathrm{K}(\mathrm{x})$ and $\mathrm{K}(\mathrm{x})-\Delta\left(\mathrm{x}\right.$ is the weight ratio of $\mathrm{K}_{2} \mathrm{CO}_{3}$ to PYR; the initial $\mathrm{KH}_{2} \mathrm{PO}_{4}$ concentration $=3 \mathrm{mmol} / \mathrm{L}$; adsorbent dose $=2 \mathrm{~g} / \mathrm{L}$; and agitation temperature $=25^{\circ} \mathrm{C}$ )

\section{Results and discussion}

\subsection{Weight ratio of $\mathrm{K}_{2} \mathrm{CO}_{3}$ to PYR}

The weight ratio of $\mathrm{K}_{2} \mathrm{CO}_{3}$ to PYROMEX (PYR) was changed in the range of $1-5$. Figure 1 shows the results of equilibrium adsorption amounts for 10 samples; $K(x)$ and $\mathrm{K}(\mathrm{x})-\Delta$, where $\mathrm{x}$ is $1-5$. In Fig. 1, K(1-5) had similar $Q_{\mathrm{e}}$ value around $0.1 \mathrm{mmol} / \mathrm{g}$, whereas $\mathrm{K}(3)-\Delta$ reached $0.23 \mathrm{mmol} / \mathrm{g}$ and was better than $\mathrm{K}(1,2,4$, and 5$)-\Delta$. These results suggest that (1) the optimum amount of $\mathrm{K}_{2} \mathrm{CO}_{3}$ was 3 times greater weight than PYR, and (2) the heat treatment at $950{ }^{\circ} \mathrm{C}$ improved the phosphate adsorption of activated carbon fiber by $25-90 \%$.

The heat treatment was done for the purpose of yielding quaternized nitrogen $(\mathrm{N}-\mathrm{Q})$ from other nitrogen species which would be the adsorption site for phosphate. The data of XPS analysis (N1s spectra) and the CHN elemental composition were shown in Table 1. The $\mathrm{N}-\mathrm{Q}$ species was increased from $0.33 \mathrm{wt} \%(\mathrm{~K}(3))$ to $0.46 \mathrm{wt} \%(\mathrm{~K}(3)-\Delta)$ owing to the $950^{\circ} \mathrm{C}$ heat treatment. This was one of the reason why $\mathrm{K}(3)-\Delta$ was better adsorbent among the samples. $\mathrm{K}(1)-\Delta$ contained high amount of not only $\mathrm{N}-\mathrm{Q}$ but also $\mathrm{N}-\mathrm{X}$ compared to $\mathrm{K}(3)-\Delta$. $\mathrm{N}-\mathrm{X}$ contains $\mathrm{N}^{+}-\mathrm{O}^{-}$which would prevent phosphate from approaching to adsorbent surface. $\mathrm{K}(5)-\Delta$ contained the lowest amount of $\mathrm{N}-\mathrm{Q}$ and $\mathrm{N}$ among the heat-treated samples. The increase in the weight ratio of $\mathrm{K}_{2} \mathrm{CO}_{3}$ caused the decrease in $\mathrm{N}$ content. It means that the adsorption amount would be $\mathrm{K}(5)-\Delta<\mathrm{K}(3)-\Delta<\mathrm{K}(1)-\Delta$. However, the $Q_{e}$ was not in proportion to $N$ content.

Table 2 shows the specific surface area and pore structure of the samples. The $S_{\mathrm{BET}}$ of $\mathrm{K}(1)$ was the highest $\left(2043 \mathrm{~m}^{2} / \mathrm{g}\right)$, because the pore structure was developed better than $\mathrm{K}(3)$ and $\mathrm{K}(5)$. In contrast, after heat treatment at $950{ }^{\circ} \mathrm{C}, \mathrm{K}(5)-\triangle$ showed the highest $S_{\mathrm{BET}}$ and pore volume. $K(1)-\Delta$ lost its surface area to less than $1000 \mathrm{~m}^{2} / \mathrm{g}$ and
Table 1 The characteristics of activated carbons

\begin{tabular}{|c|c|c|c|c|c|c|c|c|}
\hline \multirow[t]{2}{*}{ Sample } & \multicolumn{4}{|c|}{ XPS analysis (wt\%) } & \multicolumn{4}{|c|}{ Elemental analysis (wt\%) } \\
\hline & $\mathrm{N}-6$ & $N-5$ & $\mathrm{~N}-\mathrm{Q}$ & $\mathrm{N}-\mathrm{X}$ & C & $\mathrm{H}$ & $\mathrm{N}$ & $\mathrm{O}^{\mathrm{a}}$ \\
\hline $\mathrm{K}(1)$ & - & - & - & - & 74.8 & 0.5 & 6.7 & 18.0 \\
\hline $\mathrm{K}(3)$ & 0.14 & 0.49 & 0.33 & 0.11 & 89.4 & $<0.1$ & 0.9 & 9.6 \\
\hline $\mathrm{K}(5)$ & - & - & - & - & 89.1 & $<0.1$ & 0.6 & 10.2 \\
\hline$K(1)-\Delta$ & 0.19 & 0.19 & 0.50 & 0.30 & 87.9 & $<0.1$ & 1.3 & 10.7 \\
\hline $\mathrm{K}(3)-\Delta$ & 0.30 & 0.40 & 0.46 & 0.19 & 90.0 & $<0.1$ & 1.2 & 8.7 \\
\hline$K(5)-\Delta$ & 0.05 & 0.24 & 0.25 & 0.20 & 85.6 & $<0.1$ & 0.5 & 13.8 \\
\hline
\end{tabular}

a By balance

\begin{tabular}{llllll}
\hline Sample & $S_{\text {BET }}\left(\mathrm{m}^{2} / \mathrm{g}\right)$ & $V_{\text {total }}\left(\mathrm{cm}^{3} / \mathrm{g}\right)$ & $V_{\text {micro }}\left(\mathrm{cm}^{3} / \mathrm{g}\right)$ & $V_{\text {meso }}^{\mathrm{a}}\left(\mathrm{cm}^{3} / \mathrm{g}\right)$ & $D_{\text {avg }}(\mathrm{nm})$ \\
\hline $\mathrm{K}(1)$ & 2043 & 0.998 & 0.991 & 0.007 & 1.95 \\
$\mathrm{~K}(3)$ & 1723 & 0.807 & 0.801 & 0.007 & 1.87 \\
$\mathrm{~K}(5)$ & 1800 & 0.675 & 0.669 & 0.006 & 1.82 \\
$\mathrm{~K}(1)-\Delta$ & 874 & 0.411 & 0.407 & 0.004 & 1.88 \\
$\mathrm{~K}(3)-\Delta$ & 1277 & 0.559 & 0.553 & 0.006 & 1.75 \\
$\mathrm{~K}(5)-\Delta$ & 1943 & 0.911 & 0.905 & 0.007 & 1.92
\end{tabular}

a By balance
Table 2 The specific surface area and pore structures of activated carbons 


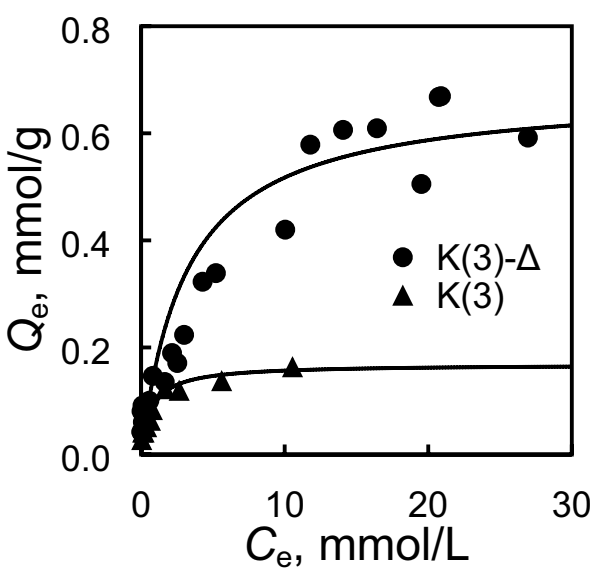

Fig. 2 The phosphate adsorption isotherm of $\mathrm{K}(3)-\Delta$ and $\mathrm{K}(3)$ (the initial $\mathrm{KH}_{2} \mathrm{PO}_{4}$ concentration $=0.1-30 \mathrm{mmol} / \mathrm{L}$; adsorbent dose $=2 \mathrm{~g} / \mathrm{L}$; contact time $=24 \mathrm{~h}$; and agitation temperature $=25^{\circ} \mathrm{C}$ )

could not improve the adsorption capacity, while K(3)- $\Delta$ increased the $Q_{e}$ from $K(3)$, which was as much phosphate adsorption amount as $K(1)$. Furthermore, the results shown in Tables 1 and 2 would suggest that although $K(1)$ was activated well leading to the largest specific surface area, the carbon structure was not strict enough causing the large decrease in $S_{\mathrm{BET}}, V_{\text {total }}, V_{\text {micro, }}, V_{\text {meso, }}$ and $\mathrm{N}$ content through the $950^{\circ} \mathrm{C}$ heat treatment. On the other hand, $\mathrm{K}(3)$ and $\mathrm{K}(5)$ were damaged mildly and preserved their $S_{\mathrm{BET}}$ and $\mathrm{N}$ content.
According to these results, (1) the amount of $\mathrm{N}-\mathrm{Q}$ and (2) the specific surface area were essential for phosphate adsorption. However, these points could not explain the reason why $\mathrm{K}(3)-\Delta$ was better adsorbent than $\mathrm{K}(3)$. $\mathrm{K}(3)$ was better than $\mathrm{K}(3)-\Delta$ from the viewpoints of $S_{\mathrm{BET}}$, pore volume, and the ratio of $\mathrm{N}-\mathrm{Q}$ to $\mathrm{N}-\mathrm{X}$, which were 3 for $\mathrm{K}(3)$ and 2.4 for $K(3)-\Delta$, while the calculated $N-Q$ amount on a unit area was 0.008 and $0.015\left(\mathrm{~mol} / 6.022 \times 10^{23} \mathrm{~nm}^{2}\right)$ in $\mathrm{K}(3)$ and $\mathrm{K}(3)-\Delta$, respectively. The number of $\mathrm{N}-\mathrm{Q}$ per $1 \mathrm{~nm}^{2}$ could lead to the increase in $Q_{e}$ of $K(3)-\Delta$ compared to $K(3)$.

\subsection{Adsorption isotherms and kinetics}

The Langmuir adsorption isotherm curves were illustrated in Fig. 2 and their parameters were tabulated in Table 3. The maximum adsorption capacity $\left(Q_{m}\right)$ of phosphate by $\mathrm{K}(3)-\Delta$ reached $0.68 \mathrm{mmol} / \mathrm{g}$ and the value of the equilibrium adsorption affinity $\left(K_{\mathrm{e}}\right)$ was $0.32 \mathrm{~L} / \mathrm{mmol}$ (Table 3 ). Meanwhile, $K(3)$ showed very low $Q_{\mathrm{m}}(0.16 \mathrm{mmol} / \mathrm{g})$ but its $K_{\mathrm{e}}(1.37 \mathrm{~L} / \mathrm{mmol})$ was higher than $\mathrm{K}(3)-\Delta$ because $\mathrm{K}(3)$ shown higher $S_{\mathrm{BET}}$ and pore volume. Apparently, the $950^{\circ} \mathrm{C}$ heat treatment was quite efficient to improve the phosphate adsorption capacity for $\mathrm{K}(3)$ due to increase the amount of adsorption sites, whereas it slightly decreased the surface structure and $K_{\mathrm{e}}$. The maximum adsorption capacity for various adsorbents was summarized in Table 4. Among adsorbents including activated carbon, $\mathrm{K}(3)-\Delta \mathrm{had}$ a great adsorption ability.

The results of adsorption kinetics were shown in Fig. 3, and the parameters of pseudo-first- and second-order
Table 3 The parameters of adsorption isotherm and pseudo-first- and second-order model for kinetics

\begin{tabular}{|c|c|c|c|c|c|c|c|c|}
\hline \multirow[t]{3}{*}{ Sample } & \multicolumn{3}{|c|}{ Adsorption isotherm } & \multicolumn{5}{|c|}{ Kinetics } \\
\hline & \multirow[t]{2}{*}{$Q_{\mathrm{m}}(\mathrm{mmol} / \mathrm{g})$} & \multirow[t]{2}{*}{$K_{\mathrm{e}}(\mathrm{L} / \mathrm{mmol})$} & \multirow[t]{2}{*}{$\mathrm{R}^{2}$} & \multicolumn{2}{|c|}{$\begin{array}{l}\text { Pseudo-first- } \\
\text { order }\end{array}$} & \multicolumn{3}{|c|}{ Pseudo-second-order } \\
\hline & & & & $k_{1}(/ \mathrm{h})$ & $\mathrm{R}_{1}^{2}$ & $k_{2}(/ \mathrm{h})$ & $Q_{\mathrm{e} 2}(\mathrm{mmol} / \mathrm{g})$ & $\mathrm{R}_{2}^{2}$ \\
\hline $\mathrm{K}(3)$ & 0.16 & 1.37 & 0.908 & 1.21 & 0.462 & 97.3 & 0.11 & 0.993 \\
\hline $\mathrm{K}(3)-\Delta$ & 0.68 & 0.32 & 0.924 & 3.42 & 0.455 & 68.6 & 0.22 & 0.998 \\
\hline
\end{tabular}

\begin{tabular}{lllll}
\hline Adsorbents & Chemical & Conditions & $Q_{\mathrm{m}}$ (mmol/g) & References \\
\hline $\mathrm{Fe}-\mathrm{CaCl}_{2}$ PVA & $\mathrm{CaCl}_{2}$ & $\mathrm{pH}$ & 0.61 & {$[19]$} \\
$\mathrm{Fe}-\mathrm{MgCl}_{2}$ PVA & $\mathrm{MgCl}_{2}$ & $\mathrm{pH} 7$ & 0.35 & {$[19]$} \\
$\mathrm{Fe}-\mathrm{Mn}$ oxide & $\mathrm{FeSO}_{4}$ & $25^{\circ} \mathrm{C}, \mathrm{pH} \mathrm{7}$ & 0.17 & {$[20]$} \\
Zeolite & $\mathrm{LaCl}_{3}$ & $20^{\circ} \mathrm{C}$ & 0.64 & {$[22]$} \\
Al-biochar & $\mathrm{AlCl}_{3}$ & $\mathrm{pH} 6$ & 0.50 & {$[23]$} \\
Prosopis juliflora-based AC & $\mathrm{H}_{2} \mathrm{SO}_{4}$ & $30^{\circ} \mathrm{C}, \mathrm{pH} 6.7$ & 0.14 & {$[24]$} \\
Fe-AC (commercial) & - & $22^{\circ} \mathrm{C}, \mathrm{pH} 6.5$ & 0.11 & {$[25]$} \\
Lanthanum-ACF (commercial) & $\mathrm{La}\left(\mathrm{NO}_{3}\right)_{3}$ & $10^{\circ} \mathrm{C}$ & 0.08 & {$[26]$} \\
PAN-based ACF & $\mathrm{steam}^{\circ}$ & $25^{\circ} \mathrm{C}$ & 0.22 & {$[35]$} \\
PAN-based ACF & $\mathrm{K}_{2} \mathrm{CO}_{3}$ & $25^{\circ} \mathrm{C}$ & 0.68 & This study \\
\hline
\end{tabular}

Table 4 Phosphate adsorption by some other adsorbents 


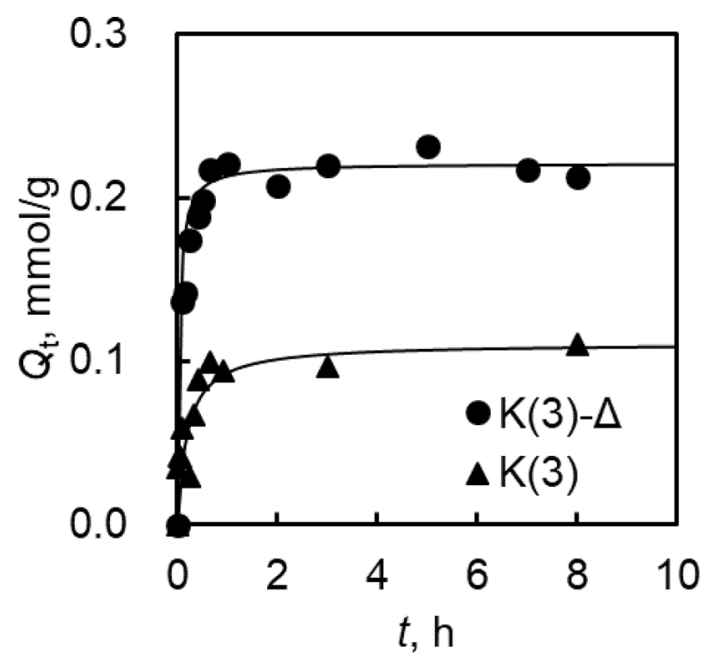

Fig. 3 The phosphate adsorption rate onto $\mathrm{K}(3)$ and $\mathrm{K}(3)-\Delta$ (the initial $\mathrm{KH}_{2} \mathrm{PO}_{4}$ concentration $=3 \mathrm{mmol} / \mathrm{L}$; adsorbent dose $=2 \mathrm{~g} / \mathrm{L}$; and agitation temperature $=25^{\circ} \mathrm{C}$ )

were presented in Table 3. The adsorption curve in Fig. 3 was calculated and illustrated using pseudo-secondorder model $\left(k_{2}\right.$ and $\left.Q_{\mathrm{e} 2}\right)$ [43]. As can be seen in Fig. 3, the phosphate adsorption for both $\mathrm{K}(3)$ and $\mathrm{K}(3)-\Delta$ reached $90 \%$ of its adsorption amount $\left(Q_{\mathrm{e}}\right)$ within $15 \mathrm{~min}$ and equilibrium within $1 \mathrm{~h}$. Based on their coefficient value, pseudo-second-order model was well fitted to both adsorbents.

\subsection{Effect of pH on phosphate adsorption}

The plots of equilibrium $\mathrm{pH}\left(\mathrm{pH}_{\mathrm{e}}\right)$ and $\mathrm{Q}_{\mathrm{e}}$ were shown in Fig. 4. In order to adjust the solution $\mathrm{pH}, 1 \mathrm{~mol} / \mathrm{L} \mathrm{HCl}$ or $\mathrm{NaOH}$ was used. Various initial $\mathrm{pH}\left(1<\mathrm{pH}_{0}<11\right)$ greatly affected the adsorption capacities. Generally, phosphate adsorption reaches maximum amount under acidic condition, whereas basic condition causes low removal ability due to increasing $\mathrm{OH}^{-}$[44]. Moreover, the dominant phosphate ion species are governed by the solution $\mathrm{pH}$. Figure 4 showed that $\mathrm{H}_{2} \mathrm{PO}_{4}^{-}$was preferable species for $\mathrm{N}-\mathrm{Q}$ under $2<\mathrm{pH}<7$ rather than $\mathrm{H}_{3} \mathrm{PO}_{4}, \mathrm{HPO}_{4}{ }^{2-}$, and $\mathrm{PO}_{4}{ }^{3-}$. The $Q_{\mathrm{e}}$ of $\mathrm{K}(3)$ and $\mathrm{K}(3)-\Delta$ was increased to 0.12 and $0.23 \mathrm{mmol} / \mathrm{g}$, respectively, with increasing $\mathrm{pH}$ up to 5-6. In the $\mathrm{pH} 6-8, \mathrm{~K}(3)-\Delta$ remained its adsorption amount around $0.2 \mathrm{mmol} / \mathrm{g}$, though the $Q_{\mathrm{e}}$ of K(3) and K(3)- $\Delta$ decreased at $\mathrm{pH}$ of higher than 6 and 8 , respectively. Larger amount of hydroxyl ion would also prevent phosphate ion from adsorption onto N-Q site. Additionally, the surface of activated carbon fiber would be negatively charged at higher than $\mathrm{pH}$ of point zero charge $\left(\mathrm{pH}_{\mathrm{pzc}}\right)$. In this study, the $\mathrm{pH}_{\mathrm{pzc}}$ of $\mathrm{K}(3)$ and $\mathrm{K}(3)-\Delta$ was obtained from the plots of $\mathrm{pH}_{0}$ versus $\mathrm{pH}_{\mathrm{e}}[45]$, and they were about 6.5 and 8.0,

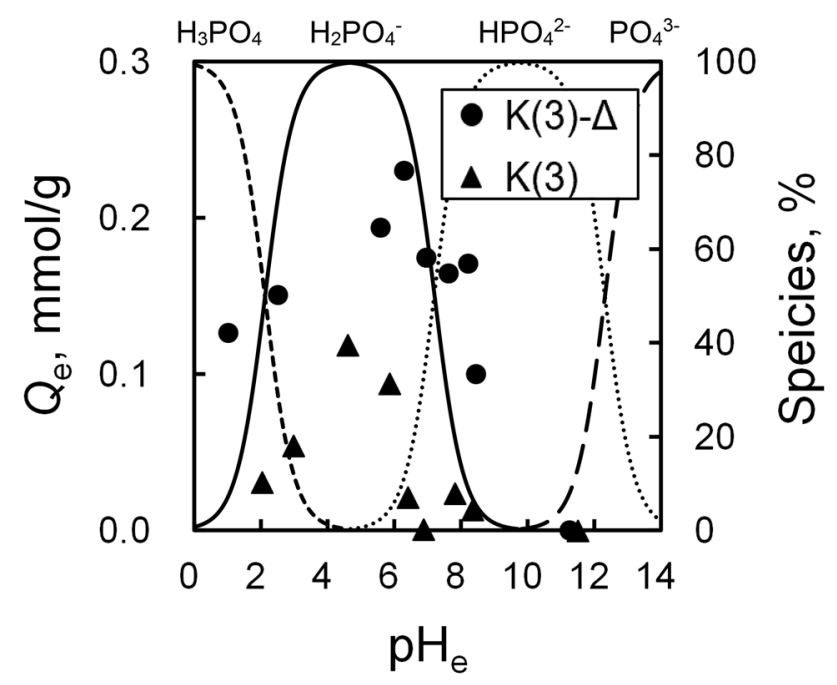

Fig. 4 The effect of $\mathrm{pH}$ on phosphate adsorption for $\mathrm{K}(3)$ and $\mathrm{K}(3)-\Delta$, and phosphate species (the initial $\mathrm{KH}_{2} \mathrm{PO}_{4}$ concentration $=3 \mathrm{mmol} / \mathrm{L}$; adsorbent dose $=2 \mathrm{~g} / \mathrm{L}$; and agitation temperature $=25^{\circ} \mathrm{C}$ )

respectively. These results might indicate that phosphate adsorption onto $\mathrm{N}-\mathrm{Q}$ of activated carbon fiber was improved in the $\mathrm{pH}$ range between 5 and 8 , and inhibited under basic conditions.

\subsection{Desorption}

The calculated adsorption amount ratio $\left(Q_{e, 2 n d} / Q_{e, 1 s t}[\%]\right)$ was shown in Fig. 5 to examine the desorption ability of $\mathrm{K}(3)-\Delta$. In Fig. 5, $\mathrm{HCl}(3 \mathrm{rd}, 1 \mathrm{M})$ imitates to the $Q_{\mathrm{e}}$ proportion of third adsorption amount to first one $\left(Q_{e, 3 r d} / Q_{e, 1 s t}\right.$ [\%]) and the $\Delta$ is the heat desorption method. Among the desorption methods using chemicals, the desorption with $\mathrm{HCl}$ was better efficient than that with $\mathrm{NaCl}$ and $\mathrm{NaOH}$. This result suggested that regeneration under acid condition and exchanging $\mathrm{H}_{2} \mathrm{PO}_{4}^{-}$to $\mathrm{Cl}^{-}$easily compared to $\mathrm{OH}^{-}$were advantageous for $\mathrm{K}(3)-\Delta$. The $\mathrm{HCl}$ concentration for desorption also influenced the second cycle adsorption amount. It could be inferred that lower $\mathrm{Cl}^{-}$concentration and stronger acid condition caused poor desorption ability ( $<40 \%)$. On the other hand, the $\mathrm{K}(3)-\Delta$ could adsorb phosphate by about $80 \%$ of its first adsorption amount after desorption with $1 \mathrm{~mol} / \mathrm{L} \mathrm{HCl}$ solution, and it could adsorb $60 \%$ at the third adsorption experiment. The desorption amount by heating at $950^{\circ} \mathrm{C}$ would mean the maximum desorption ability because the ion binding between phosphate and $\mathrm{N}-\mathrm{Q}$ would be decomposed absolutely during $950{ }^{\circ} \mathrm{C}$ heat treatment, and re-adsorption reached over $80 \%$. The reason why 


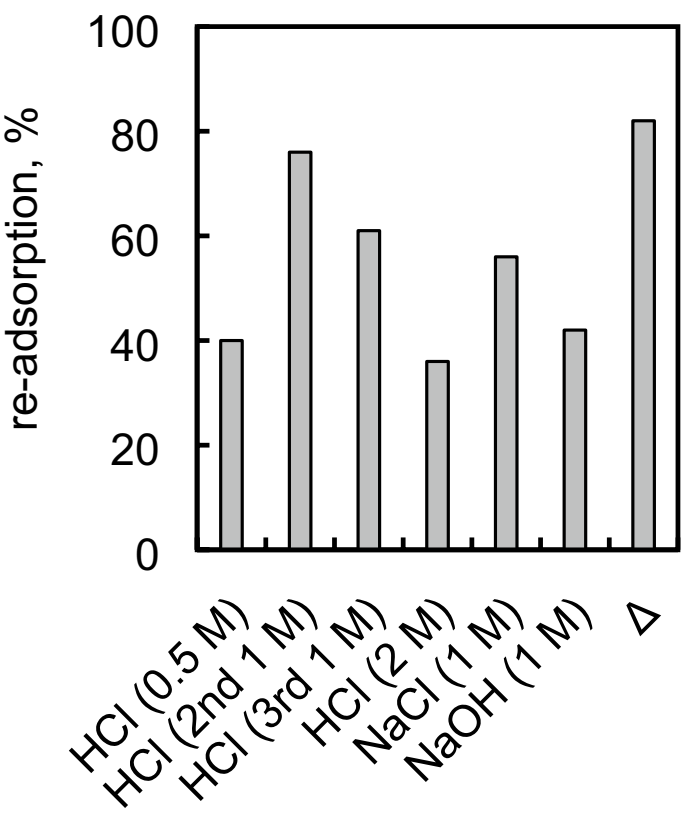

Fig. 5 The desorption experiments for $\mathrm{K}(3)-\Delta$ (1st adsorption $=100 \%$, the initial $\mathrm{KH}_{2} \mathrm{PO}_{4}$ concentration $=3 \mathrm{mmol} / \mathrm{L}$; adsorbent dose $=2 \mathrm{~g} / \mathrm{L} ;$ and agitation temperature $=25^{\circ} \mathrm{C}$ )

$\mathrm{K}(3)-\Delta$ lost $20 \%$ adsorption amount would be a little decrease in N content and N-Q. Compared to this result, $1 \mathrm{~mol} / \mathrm{L} \mathrm{HCl}$ could be supposed to desorb phosphate ion almost completely. For the regeneration of $\mathrm{K}(3)-\Delta$, $1 \mathrm{~mol} / \mathrm{L} \mathrm{HCl}$ was better solution to desorb phosphate.

\section{Conclusions}

$\mathrm{K}_{2} \mathrm{CO}_{3}$ activation was effective for $\mathrm{PYR}$, and the weight ratio of $\mathrm{K}_{2} \mathrm{CO}_{3} / \mathrm{PYR}$ for the activation was related to specific surface area. The highest adsorption amount of $0.23 \mathrm{mmol} / \mathrm{g}$ was achieved for $\mathrm{K}(3)-\Delta$, which was activated at the weight ratio of 3 to PYR and then heated at $950^{\circ} \mathrm{C}$ for $30 \mathrm{~min}$. The phosphate adsorption would depend on three parameters; specific surface area $\left(\mathrm{m}^{2} / \mathrm{g}\right)$, nitrogen content $(\mathrm{wt} \%)$, and the number of $\mathrm{N}-\mathrm{Q}$ on a unit area $\left(\mathrm{mol} / 6.022 \times 10^{23} \mathrm{~nm}^{2}\right) . \mathrm{K}(3)-\Delta$ exhibited relatively high phosphate adsorption capacity $(0.68 \mathrm{mmol} / \mathrm{g})$ and rapid adsorption rate to reach equilibrium $(<1 \mathrm{~h})$ as well. Furthermore, $\mathrm{HCl}$ acid was effective regeneration agent to desorb phosphate from $\mathrm{K}(3)-\Delta$.

Acknowledgements We thank Prof. Dr. Fumio Imazeki, the head of Safety and Health Organization, Chiba University, for the financial support on our study.

\section{Compliance with ethical standards}

Conflict of interest The authors declare that they have no conflict of interest.

\section{References}

1. Joe MM, Deivaraj S, Benson A, Henry AJ, Narendrakumar G (2018) Soil extract calcium phosphate media for screening of phosphate-solubilizing bacteria. Agric Nat Resour 52(3):305-308

2. Jain P, Arora N, Juhi M, Pruthi V, Majumder CB (2017) Pretreated algal bloom as a substantial nutrient source for microalgae cultivation for biodiesel production. Bioresour Technol 242:152-160

3. Zeng J, Yin B, Wang Y, Huai B (2019) Significantly decreasing harmful algal blooms in China seas in the early 21 st century. Mar Pollut Bull 139:270-274

4. Results of the FY 2017 Water Quality Survey of Public Water Areas (2018) Ministry of the Environment Water and Atmospheric Environment Bureau

5. Environmental White Paper of FY 2017 (2018) Chiba prefecture government

6. Gamshadzehi E, Nassiri M, Ershadifar H (2019) One-pot synthesis of microporous $\mathrm{Fe}_{2} \mathrm{O}_{3} / \mathrm{g}-\mathrm{C}_{3} \mathrm{~N}_{4}$ and its application for efficient removal of phosphate from sewage and polluted seawater. Colloids Surf A 567:7-15

7. Adam A, Mohammad-Noor N, Anton A, Saleh E, Saad S, Shaleh SRM (2011) Temporal and spatial distribution of harmful algal bloom (HAB) species in coastal waters of Kota Kinabalu, Sabah, Malaysia. Harmful Algae 10:495-502

8. Nguyen TTN, Némery J, Gratiot N, Strady E, Tran VQ, Nguyen AT, Aimé J, Peyne A (2019) Nutrient dynamics and eutrophication assessment in the tropical river system of Saigon-Dongnai (southern Vietnam). Sci Total Environ 653:370-383

9. Wen Z, Zhang Y, Dai C (2014) Removal of phosphate from aqueous solution using nanoscale zerovalent iron ( $\mathrm{nZVI}$ ). Aspects 457:433-440

10. West M, Fenner N, Gough R, Freeman C (2017) Evaluation of algal bloom mitigation and nutrient removal in floating constructed wetlands with different macrophyte species. Ecol Eng 108:581-588

11. Cheng $P$, Chen D, Liu H, Zou X, Wu Z, Xie J, Qing C, Kong D, Chen $T$ (2018) Synergetic effects of anhydrite and brucite-periclase materials on phosphate removal from aqueous solution. J Mol Liq 254:145-153

12. Yan $Y$, Tianhu $C$, Xun $Z$, Chengsong $Q$, Jin W, Zhengbo $Y$, Haibo L, Zhe Y (2018) Simultaneous removal of nitrate and phosphate from wastewater by siderite based autotrophic denitrification. Chemosphere 199:130-137

13. Yuan J, Li Y, Chen S, Li D, Tang H, Chadwick D, Li S, Li W, Li G (2018) Effects of phosphogypsum, superphosphate, and dicyandiamide on gaseous emission and compost quality during sewage sludge composting. Bioresour Technol 270:368-376

14. Boeykens SP, Piol MN, Samudio Legal L, Saralegui AB, Vázquez $C$ (2017) Eutrophication decrease: phosphate adsorption processes in presence of nitrates. J Environ Manag 203:888-895

15. Park J-H, Wang JJ, Xiao R, Zhou B, Delaune RD, Seo D-Ch (2018) Effect of pyrolysis temperature on phosphate adsorption characteristics and mechanisms of crawfish char. J Colloid Interface Sci 525:143-151

16. Hu F, Wang M, Peng X, Qiu F, Zhang T, Dai H, Liu Z, Cao Z (2018) High-efficient adsorption of phosphates from water by hierarchical CuAl/biomass carbon fiber layered double hydroxide. Colloids Surf A 550:314-323

17. Shang Y, Guo K, Jiang P, Xu X, Gao B (2018) Adsorption of phosphate by the cellulose-based biomaterial and its sustained release of laden phosphate in aqueous solution and soil. Int J Biol Macromol 109:524-534

18. Suresh Kumar $P$, Korving L, Keesman KJ, van Loosdrecht MCM, Witkamp G-J (2019) Effect of pore size distribution and 
particle size of porous metal oxides on phosphate adsorption capacity and kinetics. Chem Eng J 358:160-169

19. Han C, Lalley J, Iyanna N, Nadagoude MN (2017) Removal of phosphate using calcium and magnesium-modified iron-based adsorbents. Mater Chem Phys 198:115-124

20. Xiaoli D, Qiang H, Junqi L, Haiyan L (2017) The behavior of phosphate adsorption and its reactions on the surfaces of Fe-Mn oxide adsorbent. J Taiwan Inst Chem E 76:167-175

21. Wang X-H, Liu F-F, Lu L, Yang S, Zhao Y, Sum L-B, Wang S-G (2013) Individual and competitive adsorption of $\mathrm{Cr}(\mathrm{VI})$ and phosphate onto synthetic Fe-Al hydroxides. Colloids Surf A 423:42-49

22. Goscianska J, Ptaszkowska-Koniarz M, Frankowski M, Franus M, Panek R, Franus W (2018) Removal of phosphate from water by lanthanum-modified zeolites obtained from fly ash. J Colloid Interface Sci 513:72-81

23. Yin $\mathrm{Q}$, Ren $\mathrm{H}$, Wang R, Zhao Z (2018) Evaluation of nitrate and phosphate adsorption on Al-modified biochar: influence of $\mathrm{Al}$ content. Sci Total Environ 631-632:895-903

24. Manjunath SV, Kumar M (2018) Evaluation of single-component and multi-component adsorption of metronidazole, phosphate and nitrate on activated carbon from Prosopıs julıflora. Chem Eng J 346:525-534

25. Suresh Kumar $P$, Prot $T$, Korving $L$, Keesman KJ, Dugulan I, van Loosdrecht MCM, Witkamp G-J (2017) Effect of pore size distribution on iron oxide coated granular activated carbons for phosphate adsorption-importance of mesopores. Chem Eng J 326:231-239

26. Liu J, Wan L, Zhang L, Zhou Q (2011) Effect of $\mathrm{pH}$, ionic strength, and temperature on the phosphate adsorption onto lanthanum-doped activated carbon fiber. J Colloid Interface Sci 364:490-496

27. El-Bouraie M, Masoud AA (2017) Adsorption of phosphate ions from aqueous solution by modified bentonite with magnesium hydroxide $\mathrm{Mg}(\mathrm{OH})_{2}$. Appl Clay Sci 140:157-164

28. Suresh Kumar P, Ejerssa WW, Wegener CC, Korving L, Dugulan Al, Temmink H, van Loosdrecht MCM, Witkamp G-J (2018) Understanding and improving the reusability of phosphate adsorbents for wastewater effluent polishing. Water Res 145:365-374

29. Li J-R, Wang F-K, Xiao H, Xu L, Fu M-L (2019) Layered chalcogenide modified by lanthanum, calcium and magnesium for the removal of phosphate from water. Colloids Surf A 560:306-314

30. Sendrowski A, Boyer TH (2013) Phosphate removal from urine using hybrid anion exchange resin. Desalination 322:104-112

31. Pels JR, Kapteijn F, Moulijn JA, Zhu Q, Thomas KM (1995) Evolution of nitrogen functionalities in carbonaceous materials during pyrolysis. Carbon 33(11):1641-1653

32. Furuyado M, Ahmad Zaini MA, Aikawa M, Amano Y, Machida M (2010) Adsorption of Cd(II) on activated carbon fiber prepared from polyacrylonitrile (PAN). J Environ Chem 20(4):379-384

33. Yamazaki $Y$, Gettongsong T, Mikawa M, Amano $Y$, Machida M (2016) Adsorptive removal of phosphate from water by ammonia gas activated polyacrylonitrile fiber. J Fiber Sci Technol 72(11):237-243

34. Zyoud A, Nassar HNI, El-Hamouz A, Hilal SH (2015) Solid olive waste in environmental cleanup: enhanced nitrite ion removal by $\mathrm{ZnCl}_{2}$-activated carbon. J Environ Manag 152:27-35

35. Ello AS, De Souza LKC, Trokourey A, Jaroniec M (2013) Development of microporous carbons for $\mathrm{CO}_{2}$ capture by $\mathrm{KOH}$ activation of African palm shells. J CO2 Util 2:35-38

36. Pallarés J, González-Cencerrado A, Arauzo I (2018) Production and characterization of activated carbon from barley straw by physical activation with carbon dioxide and steam. Biomass Bioenergy 115:64-73

37. Montes V, Hill JM (2018) Activated carbon production: recycling $\mathrm{KOH}$ to minimize waste. Mater Lett 220:238-240

38. Sakamoto T, Amano Y, Machida M (2017) Phosphate ion adsorption properties of polyacrylonitrile (PAN) activated carbon fiber. J Fiber Sci Technol 73(9):222-228

39. Lozano-Castello D, Calo JM, Cazorla-Amorós D, Linares-Solano A (2007) Carbon activation with $\mathrm{KOH}$ as explored by temperature programed techniques, and the effects of hydrogen. Carbon 45:2529-2536

40. Huang Y, Ma E, Zhao G (2015) Thermal and structure analysis on reaction mechanisms during the preparation of activated carbon fibers by $\mathrm{KOH}$ activation from liquefied wood-based fibers. Ind Crop Prod 69:447-455

41. De Lima ACA, Nascimento RF, De Sousa FF, Filho JM, Oliveira AC (2012) Modified coconut shell fibers: a green and economical sorbent for the removal of anions from aqueous solutions. Chem Eng J 185-186:274-284

42. Sing KSW (1989) The use of physisorption for the characterization of microporous carbons. Carbon 27:5-11

43. Qian J, Shen M, Wang P, Wang C, Li K, Liu J, Lu B, Tian X (2017) Perfluorooctane sulfonate adsorption on powder activated carbon: effect of phosphate $(\mathrm{P})$ competition, $\mathrm{pH}$, and temperature. Chemosphere 182:215-222

44. Fu C-C, Tran HN, Chen X-H, Juang R-S (2020) Preparation of polyaminated $\mathrm{Fe}_{3} \mathrm{O}_{4} @$ chitosan core-shell magnetic nanoparticles for efficient adsorption of phosphate in aqueous solutions. J Ind Eng Chem 83:235-246

45. Choi Y-K, Kan E (2019) Effects of pyrolysis temperature on the physicochemical properties of alfalfa-derived biochar for the adsorption of bisphenol $A$ and sulfamethoxazole in water. Chemosphere 218:741-748

Publisher's Note Springer Nature remains neutral with regard to jurisdictional claims in published maps and institutional affiliations. 